\title{
A Semi-Analytical Solution for Large-Scale Injection-Induced Pressure Perturbation and Leakage in a Laterally Bounded Aquifer-Aquitard System
}

\author{
Quanlin Zhou*, Jens T. Birkholzer, and Chin-Fu Tsang \\ Earth Sciences Division, Lawrence Berkeley National Laboratory, \\ University of California, Berkeley, CA 94720, USA \\ *Corresponding Author, Tel: 1-510-486-5748, Fax: 1-510-486-5686; Email: \\ qzhou@lbl.gov, Mail Address: One Cyclotron Road, MS 90-1116
}




\begin{abstract}
A number of (semi-)analytical solutions are available to drawdown analysis and leakage estimation of shallow aquifer-aquitard systems. These solutions assume that the systems are laterally infinite. When a large-scale pumping from (or injection into) an aquiferaquitard system of lower specific storativity occurs, induced pressure perturbation (or hydraulic head drawdown/rise) may reach the lateral boundary of the aquifer. We developed semi-analytical solutions to address the induced pressure perturbation and vertical leakage in a "laterally bounded" system consisting of an aquifer and an overlying/underlying aquitard. A one-dimensional radial flow equation for the aquifer was coupled with a one-dimensional vertical flow equation for the aquitard, with a noflow condition imposed on the outer radial boundary. Analytical solutions were obtained for (1) the Laplace-transform hydraulic head drawdown/rise in the aquifer and in the aquitard, (2) the Laplace-transform rate and volume of leakage through the aquiferaquitard interface integrated up to an arbitrary radial distance, (3) the transformed total leakage rate and volume for the entire interface, and (4) the transformed horizontal flux at any radius. The total leakage rate and volume depend only on the hydrogeologic properties and thicknesses of the aquifer and aquitard, as well as the duration of pumping or injection. It was proven that the total leakage rate and volume are independent of the aquifer's radial extent and wellbore radius. The derived analytical solutions for bounded systems are the generalized solutions of infinite systems. Laplace-transform solutions were numerically inverted to obtain the hydraulic head drawdown/rise, leakage rate, leakage volume, and horizontal flux for given hydrogeologic and geometric conditions of the aquifer-aquitard system, as well as injection/pumping scenarios. Application to a large-scale injection-and-storage problem in a bounded system was demonstrated.
\end{abstract}

Key words: analytical solution, pressure perturbation, leakage, groundwater flow, pumping test 


\section{Introduction}

A number of analytical or semi-analytical solutions have been developed in the past decades for analyzing drawdown induced by pumping from a permeable aquifer, which is underlain and/or overlain by aquitards. More recent solutions differ from earlier work by making less restrictive assumptions on flow conditions in the aquitard, representing more realistic aquitards, and achieving more accurate model prediction (Theis, 1935; Hantush and Jacob, 1955; Hantush, 1960; Neuman and Witherspoon, 1969; Moench, 1985; Cheng and Morohunfola, 1993; Ramakrishnan and Kuchuk, 1993). For example, Hantush (1960) accounted for the storage of the aquitards, assumed to be negligible by Hantush and Jacob (1955), and for the leakage through the aquitards from neighboring aquifers into the pumped aquifer, assumed to be negligible by Theis (1935). Moench (1985) developed a semi-analytical solution for drawdown in both the aquifer and the aquitards, by taking into account the wellbore storage and skin effect of a large-diameter pumping well. Using pumping tests, these analytical or semi-analytical solutions have been extensively applied to calibrating the hydrogeologic properties of aquifers and aquitards.

In addition, the applications of these analytical solutions have been extended to analyze pumping-induced leakage into the pumped aquifer from the aquitards and through the aquitards from neighboring aquifers (Hantush, 1964; Cheng and Morohunfola, 1993; Butler and Tsou, 2003; Zhan and Bian, 2006; Konikow and Neuzil, 2007). For example, Zhan and Bian (2006) presented a semi-analytical solution for the leakage rate and volume over the entire time domain, with closed-form analytical solutions for late steadystate conditions, by focusing on the leakage through aquitards of no storativity. In reality, however, depletion of storage in low-permeability aquitards is the source of much of the groundwater produced from many confined aquifer systems (Konikow and Neuzil, 2007). In deep sedimentary rock, high-permeability aquifers are often overlain and/or underlain by much thicker lower-permeability aquitards or seals, which may have a high capacity for storage and attenuating pressure perturbation (or hydraulic head drawdown) induced in the pumped aquifer. Similar to pumping for water supply, injection into deep aquifers often has importance to isolation of environmental wastes. 
One limitation of the existing (semi-)analytical solutions stems from the assumption that the pumped/injected aquifer is generally of infinite areal extent. This assumption may limit direct applications of the models to large-scale pumping and injection problems. For example, industrial-scale injection of carbon dioxide $\left(\mathrm{CO}_{2}\right)$ into deep sedimentary formations is currently studied as a means of mitigating greenhouse gas effects and climate change. Injection of large amount of $\mathrm{CO}_{2}$ (millions of metric tonnes) results in pressure perturbation (or hydraulic head rise) propagating as far as $100 \mathrm{~km}$ away from the injection zone (e.g., Birkholzer et al., 2008), significantly larger than the extent of the developed $\mathrm{CO}_{2}$ plume. (This large-scale impact on pressure perturbation out of the injected fluid plume) is beyond the analysis of pumping tests in many text books (Vukovic and Soro, 1992; Batu, 1998; Cheng, 2000).) Such pressure-perturbation propagation may thus encounter the formation's lateral boundaries. Numerical simulations may be employed to predict the injection-induced pressure perturbation in laterally bounded aquifers and the leakage into overlying/underlying aquitards and neighboring aquifers (e.g., Zhou et al., 2008). Alternatively, pressure perturbation and leakage in a bounded system may be obtained using image well theory with the existing solutions of infinite aquifers (Earlougher, 1977; Streltsova, 1988; Butler and Tsou, 2003). However, considering that the horizontal area of a bounded aquifer is an infinitesimal fraction of the infinite solution domain, a very large number of image wells may be needed to calculate pressure perturbation and leakage in the bounded aquifer. A simpler (semi-)analytical solution (if possible) is needed for a laterally bounded aquifer-aquitard system.

Butler and Tsou (2003) demonstrated that the total leakage rate integrated over the entire aquifer-aquitard interface may be scale invariant (i.e., independent of the radial extent of a bounded aquifer), provided that the hydrogeological and other geometric parameters and injection/pumping rate are the same. They proved this phenomenon using an infinite number of image wells and the existing Hantush-Jacob solution for infinite aquifers. Zhan and Bian (2006) employed the scale-invariance of total leakage rate to extend applications of their semi-analytical solutions for infinite aquifers to finite-size aquifers with lateral impervious boundaries. However, the question arises whether the scale invariance is applicable for any kind of hydrogeologic and geometric conditions in the 
aquifer and wellbore radius. A completely general proof of the scale-invariant phenomenon of total leakage rate is also much needed, demonstrated using an analytical solution.

This paper aims at (1) developing semi-analytical solutions for injection- (or pumping-) induced pressure perturbation and leakage in a laterally bounded aquifer with an overlying/underlying aquitard, and (2) a general proof of the scale invariance in the total leakage rate between the aquifer and aquitard.

We coupled a one-dimensional radial flow equation for the aquifer with a onedimensional vertical flow equation for the aquitard, using the continuity of pressure and flow rate at their interface. Applying Laplace transforms to the governing flow equations and their initial and boundary conditions in dimensionless form, we obtained the analytical solutions to the Laplace-transformed pressure perturbation (i.e., hydraulic head drawdown/rise) in the aquifer and the aquitard, as well as the rate and volume of leakage through the aquifer-aquitard interface. Using these solutions, we proved that the total leakage rate and volume are independent of the radial extent of the aquifer and wellbore radius. It was also demonstrated that the derived semi-analytical solutions are generalized solutions for infinite aquifers. The Laplace transforms of pressure perturbation, and leakage rate and volume were inverted numerically to obtain their counterparts in the real time domain, with an application to large-scale injection and storage.

\section{Solutions for a Laterally Bounded Aquifer-Aquitard System}

For simplification, the following development of the semi-analytical solutions was demonstrated for the aquifer-aquitard system with an underlying impervious layer (see Figure 1)—although an underlying aquitard of different hydrogeologic properties and boundary conditions at its bottom can be easily added. In this case, the pressure perturbation is caused by injection of a given volumetric rate of native fluid into the aquifer, but the solutions are really applicable to pumping-induced drawdown as well. The system consists of an aquifer of a radial extent $r_{B}$ and an overlying aquitard. The aquifer and aquitard are both assumed to be homogeneous and isotropic, with constant thicknesses $B$ and $B^{\prime}$, respectively. The injection at a constant volumetric rate, $Q$, 
occurs in the injection zone or the well of a radius $r_{w}$. This injection leads to pressure rise in the region near the injection zone in the aquifer, and the pressure perturbation then propagates laterally away from the injection zone towards the impervious lateral boundary located at radius $r_{B}$. The pressure perturbation propagates vertically through the aquitard to the top boundary of the aquitard, where either a condition of zero pressure perturbation (Case 1) or no flow (Case 2) is assumed. The pressure-perturbation propagation also leads to leakage of native fluid from the aquifer into the aquitard and through the aquitard into the overlying aquifer in Case 1. It is assumed that the aquifer's hydraulic conductivity is significantly higher than the aquitard's conductivity so that the groundwater flow in the aquifer is one-dimensional, radial, and horizontal and that the groundwater flow in the aquitard is one-dimensional and vertical. It is assumed that the native fluid and the injected fluid are of the same fluid properties (i.e., density and viscosity), constant for the entire injection period, even though the fluid compressibility is included in the specific storage parameter.

\subsection{Hydraulic Head Rise}

The governing equation for the one-dimensional radial flow in the aquifer is written as (Bear, 1972; Moench, 1985):

$$
\frac{\partial^{2} h}{\partial r^{2}}+\frac{1}{r} \frac{\partial h}{\partial r}=\frac{S_{s}}{K} \frac{\partial h}{\partial t}+w^{\prime} \quad r_{w} \leq r \leq r_{B}
$$

with

$$
w^{\prime}=\frac{q^{\prime}}{K B}=-\left.\frac{K^{\prime}}{K B} \frac{\partial h^{\prime}}{\partial z}\right|_{z=0}
$$

where $h=h(r, t)$ is the hydraulic head in the aquifer, $r$ is the radial distance from the injection-zone center, $t$ is time, $S_{s}$ is the specific storativity of the aquifer, $K$ is the hydraulic conductivity of the aquifer, $q^{\prime}(r, t)$ is the specific discharge rate through the aquifer-aquitard interface (positive for leakage from the aquifer), $w^{\prime}$ is the scaled discharge rate per unit $K B, K^{\prime}$ is the hydraulic conductivity of the aquitard, $h^{\prime}=h^{\prime}(r, z, t)$ is the hydraulic head in the aquitard, and $z$ is the vertical coordinate upward from the aquifer-aquitard interface $(z=0)$. 
The boundary conditions at the edge of the injection zone (or wellbore) and the outer radial boundary are written as follows, respectively:

$$
\begin{gathered}
-2 \pi r_{w} K B \frac{\partial h}{\partial r}=Q \text { at } r=r_{w} \\
\frac{\partial h}{\partial r}=0 \text { at } r=r_{B}
\end{gathered}
$$

The initial condition is

$$
h(r, t)=h_{i}(r) \text { at } t=0
$$

where $h_{i}(r)$ is the initial hydraulic head.

The one-dimensional vertical flow through the aquitard is written as:

$$
\frac{\partial^{2} h^{\prime}}{\partial z^{2}}=\frac{S_{s}^{\prime}}{K^{\prime}} \frac{\partial h^{\prime}}{\partial t} \quad 0 \leq z \leq B^{\prime},
$$

where $S_{s}^{\prime}$ is the specific storativity of the aquitard. The boundary conditions at the top and bottom of the aquitard are written as follows:

$$
h^{\prime}(r, z, t)=h(r, t) \text { at } z=0, t \geq 0
$$

and

$$
\left\{\begin{array}{l}
h^{\prime}(r, z, t)=h_{i}^{\prime}(r, z) \text { at } z=B^{\prime}, \quad \text { in Case } 1 \\
\frac{\partial h^{\prime}(r, z, t)}{\partial z}=0 \text { at } z=B^{\prime}, \quad \text { in Case } 2
\end{array}\right.
$$

where $h_{i}^{\prime}(r, z)$ is the specified initial condition of hydraulic head in the aquitard. Equation (2b) implies continuity in the hydraulic head at the aquifer-aquitard interface. Case 1 denotes the condition of no change in hydraulic head with time at the aquitard top, while Case 2 denotes the no-flow condition at the aquitard top.

The governing equations and their associated initial and boundary conditions in Equations (1) and (2) can be written in a dimensionless form using: 


$$
\begin{gathered}
h_{D}=\frac{4 \pi K B}{Q}\left(h-h_{i}\right), h_{D}^{\prime}=\frac{4 \pi K B}{Q}\left(h^{\prime}-h_{i}^{\prime}\right), t_{D}=\frac{K}{S_{S} B^{2}} t, r_{D}=r / B, z_{D}=z / B^{\prime}, \\
w_{D}^{\prime}=\frac{4 \pi B^{2}}{Q} q^{\prime}
\end{gathered}
$$

where $h_{D}, h_{D}^{\prime}, t_{D}, r_{D}, z_{D}$, and $w_{D}^{\prime}$ are the dimensionless variables for hydraulic head rise in the aquifer, hydraulic head rise in the aquitard, time, radial distance, vertical coordinate, and the scaled discharge rate, respectively. Introduction of these dimensionless variables into Equation (1) leads to the governing equation and its associated initial and boundary conditions written in the dimensionless form:

$$
\frac{\partial^{2} h_{D}}{\partial r_{D}{ }^{2}}+\frac{1}{r_{D}} \frac{\partial h_{D}}{\partial r_{D}}=\frac{\partial h_{D}}{\partial t_{D}}+w_{D}^{\prime} \quad r_{D w} \leq r_{D} \leq r_{D B},
$$

with

$$
\begin{aligned}
& w_{D}^{\prime}=-\left.\lambda^{2} \frac{\partial h_{D}^{\prime}}{\partial \mathrm{z}_{D}}\right|_{z_{D}=0} \\
& -\frac{\partial h_{D}}{\partial r_{D}}=\frac{2}{r_{D w}} \text { at } r_{D}=r_{D w} \\
& \frac{\partial h_{D}}{\partial r_{D}}=0 \text { at } r_{D}=r_{D B}, \\
& h_{D i}(r)=0
\end{aligned}
$$

where

$$
\lambda=\sqrt{\frac{K^{\prime} / B^{\prime}}{K / B}}
$$

$r_{D w}\left(\equiv r_{w} / B\right)$ is the dimensionless injection-zone radius, $r_{D B}\left(\equiv r_{B} / B\right)$ is the dimensionless radial extent of the aquifer, $h_{D i}(r)$ is the dimensionless initial hydraulic head rise, and $\lambda$ is a leakage parameter.

Similarly, the governing equation and its associated initial and boundary conditions, Equation (2), for the aquitard can be written in the dimensionless form: 


$$
\frac{\partial^{2} h_{D}^{\prime}}{\partial \mathrm{z}_{D}{ }^{2}}=\frac{\sigma}{\lambda^{2}} \frac{\partial{h^{\prime}}_{D}}{\partial t_{D}} \quad 0 \leq z_{D} \leq 1
$$

with the following initial and boundary conditions:

$$
\begin{gathered}
h_{D}^{\prime}\left(r_{D}, z_{D}, t_{D}\right)=h_{D}\left(r_{D}, t_{D}\right) \text { at } z_{D}=0 \text { and } t_{D} \geq 0 \\
\left\{\begin{array}{l}
h_{D}^{\prime}=0 \text { at } z_{D}=1 \text {, in Case } 1 \\
\frac{\partial h_{D}^{\prime}}{\partial z_{D}}=0 \text { at } z_{D}=1 \text {, in Case } 2 \\
h_{D i}^{\prime}(r, z)=0
\end{array}\right.
\end{gathered}
$$

where

$$
\sigma=S_{s}^{\prime} B^{\prime} / S_{s} B
$$

By applying the Laplace transform to Equation (5), the subsidiary differential equations are obtained, with boundary conditions as follows:

$$
\begin{aligned}
& \frac{\partial^{2} \overline{h_{D}^{\prime}}}{\partial z_{D}{ }^{2}}=m^{2} \overline{h_{D}^{\prime}} \quad 0 \leq z_{D} \leq 1, \\
& \overline{h_{D}^{\prime}}\left(r_{D}, z_{D}, p\right)=\overline{h_{D}}\left(r_{D}, p\right) \text { at } z_{D}=0 \\
& \overline{h_{D}^{\prime}}=0 \text { at } z_{D}=1, \text { in Case } 1 \\
& \frac{\partial \overline{h_{D}^{\prime}}}{\partial z_{D}}=0 \text { at } z_{D}=1, \text { in Case } 2
\end{aligned}
$$

where

$$
m=\sqrt{\sigma p} / \lambda
$$

$p$ is the Laplace variable, and $\bar{a}$ denotes the Laplace-transform of variable $a$.

Following Moench (1985), one obtains the solutions to $\overline{h_{D}^{\prime}}\left(r_{D}, z_{D}, p\right)$ for the aquitard: 


$$
\overline{h_{D}^{\prime}}\left(r_{D}, z_{D}, p\right)=\left\{\begin{array}{l}
\overline{h_{D}} \sinh \left[\left(1-z_{D}\right) m\right] / \sinh (m), \text { in Case } 1 \\
\overline{h_{D}} \cosh \left[\left(1-z_{D}\right) m\right] / \cosh (m), \text { in Case } 2
\end{array}\right.
$$

Therefore, the hydraulic head rise in the aquitard, $\overline{h_{D}^{\prime}}\left(r_{D}, z_{D}, p\right)$, in the Laplace domain depends on the solution of the transformed head rise in the aquifer, $\overline{h_{D}}\left(r_{D}, p\right)$. The Laplace transform of the dimensionless scaled discharge rate, $\overline{w_{D}^{\prime}}\left(r_{D}, p\right)$, in Equation (4b) is written as:

$$
\overline{w_{D}^{\prime}}\left(r_{D}, p\right)=\overline{h_{D}}\left(r_{D}, p\right) \bar{f} ; \quad \bar{f}(\lambda, m)=\left\{\begin{array}{l}
\lambda^{2} m \operatorname{coth}(m), \text { in Case } 1 \\
\lambda^{2} m \tanh (m), \text { in Case } 2
\end{array}\right.
$$

Using Equation (8), the Laplace transform of the governing equation and its associated boundary conditions for the aquifer in the dimensionless form, Eq. (4), is obtained as follows:

$$
\begin{gathered}
\frac{\partial^{2} \overline{h_{D}}}{\partial r_{D}{ }^{2}}+\frac{1}{r_{D}} \frac{\partial \overline{h_{D}}}{\partial r_{D}}=\overline{h_{D}}(p+\bar{f}) \quad r_{D w} \leq r_{D} \leq r_{D B} \\
-\frac{\partial \overline{h_{D}}}{\partial r_{D}}=\frac{2}{r_{D w} p} \text { at } r_{D}=r_{D w} \\
\frac{\partial \overline{h_{D}}}{\partial r_{D}}=0 \text { at } r_{D}=r_{D B}
\end{gathered}
$$

The general solution to Equation (9a) is given by the modified Bessel functions (Abramowitz and Stegun, 1972):

$$
\overline{h_{D}}\left(r_{D}, p\right)=A_{1} I_{0}\left(r_{D} x\right)+A_{2} K_{0}\left(r_{D} x\right)
$$

where

$$
x=\sqrt{p+\bar{f}}
$$

$I_{0}$ is the modified Bessel function of the first kind and zero order, and $K_{0}$ is the modified Bessel function of the second kind and zero order. The two coefficients, $A_{1}$ and 
$A_{2}$, are determined using the two boundary conditions in Equations (9b) and (9c). Recalling that $\partial K_{0}(y) / \partial y=-K_{1}(y)$ and $\partial I_{0}(y) / \partial y=I_{1}(y)$ leads to the solution of the Laplace-transform head rise in the aquifer:

$$
\overline{h_{D}}\left(r_{D}, p\right)=\frac{2}{r_{D w} p x} \frac{K_{1}\left(r_{D B} x\right) I_{0}\left(r_{D} x\right)+I_{1}\left(r_{D B} x\right) K_{0}\left(r_{D} x\right)}{\left[I_{1}\left(r_{D B} x\right) K_{1}\left(r_{D w} x\right)-K_{1}\left(r_{D B} x\right) I_{1}\left(r_{D w} x\right)\right]}
$$

where $I_{1}$ is the modified Bessel function of the first kind and first order, and $K_{1}$ is the modified Bessel function of second kind and first order. The derived solution in Equation (11) differs with all previous solutions in that there is one extra term in the numerator of the right-hand side, reflecting the effect of the no-flow condition at the outer radial boundary. The physical interpretation of this solution is given in Section 4 .

\subsection{Leakage through the Aquifer-Aquitard Interface}

When the hydraulic conductivity contrast $\left(K / K^{\prime}\right)$ is larger than 100 (Zhan and Bian, 2006), the essentially horizontal flow in the aquifer changes into vertical flow in the aquitard at the aquifer-aquitard interface, obeying the law of refraction of streamlines (Zhou et al., 2001). From the definition of the vertical leakage rate integrated up to an arbitrary radius $\left(r_{R}\right)$ :

$$
\Gamma_{v}\left(r_{R}, t\right)=\int_{r_{w}}^{r_{R}} 2 \pi r q^{\prime} d r=\int_{r_{w}}^{r_{R}} 2 \pi r K B w^{\prime}(r, t) d r,
$$

one obtains the dimensionless leakage rate in the time and Laplace domains:

$$
\begin{array}{r}
\Gamma_{v D}\left(r_{D R}, t_{D}\right)=\frac{1}{2} \int_{r_{D W}}^{r_{D R}} r_{D} w_{D}^{\prime} d r_{D}, \\
\overline{\Gamma_{v D}}\left(r_{D R}, p\right)=\frac{1}{2} \bar{f} \int_{r_{D W}}^{r_{D R}} r_{D} \overline{h_{D}}\left(r_{D}, p\right) d r_{D},
\end{array}
$$

where the dimensionless variables: $r_{D R}=r_{R} / B$ and $\Gamma_{v D}=\Gamma_{v} / Q$ are introduced.

Inserting the solution of $\overline{h_{D}}\left(r_{D}, p\right)$ from Equation (11) into Equation (12c), and recalling $\int y K_{0}(y) d y=-y K_{1}(y)$ and $\int y I_{0}(y) d y=y I_{1}(y) \quad$ (Abramowitz and Stegun, 1972) leads to 


$$
\overline{\Gamma_{v D}}\left(r_{D R}, p\right)=\frac{\bar{f}}{p x^{2}}\left\{1-\frac{r_{D R}\left[I_{1}\left(r_{D B} x\right) K_{1}\left(r_{D R} x\right)-K_{1}\left(r_{D B} x\right) I_{1}\left(r_{D R} x\right)\right]}{r_{D w}\left[I_{1}\left(r_{D B} x\right) K_{1}\left(r_{D w} x\right)-K_{1}\left(r_{D B} x\right) I_{1}\left(r_{D w} x\right)\right]}\right\}
$$

The accumulative volume of water, $V_{v}\left(r_{R}, t\right)$, leaking through the aquifer-aquitard interface within the radius of $r_{R}$ from the edge of the injection zone is defined as the integrated leakage from 0 to time $t$ (Zhan and Bian, 2006). Similarly, one obtains

$$
\begin{aligned}
& V_{v}\left(r_{R}, t\right)=\int_{0}^{t} \Gamma_{v}\left(r_{R}, \tau\right) d \tau, \\
& V_{v D}\left(r_{D R}, t_{D}\right)=\int_{0}^{t_{D}} \Gamma_{v D}\left(r_{D R}, \tau\right) d \tau, \\
& \overline{V_{v D}}\left(r_{D R}, t_{D}\right)=\frac{1}{p} \overline{\Gamma_{v D}}\left(r_{D R}, t_{D}\right),
\end{aligned}
$$

where the dimensionless leakage volume: $V_{v D}\left(r_{D R}, t_{D}\right)=\frac{K}{S_{S} B^{2} Q} V_{v}\left(r_{R}, t\right)$ is introducted.

\subsection{Total Horizontal Flux}

On the basis of the definition of the total horizontal flux, $\Gamma_{h}(r, t)$, across the thickness of the aquifer at radius $r$ and time $t$ :

$$
\Gamma_{h}(r, t)=2 \pi r B q_{h}=-2 \pi r B K \frac{\partial h}{\partial r},
$$

one can easily obtain

$$
\begin{gathered}
\Gamma_{h D}\left(r_{D}, t_{D}\right)=-\frac{1}{2} r_{D} \frac{\partial h_{D}}{\partial r_{D}}, \\
\overline{\Gamma_{h D}}\left(r_{D}, p\right)=\frac{r_{D}}{r_{D w} p} \frac{I_{1}\left(r_{D B} x\right) K_{1}\left(r_{D} x\right)-K_{1}\left(r_{D B} x\right) I_{1}\left(r_{D} x\right)}{\left[I_{1}\left(r_{D B} x\right) K_{1}\left(r_{D w} x\right)-K_{1}\left(r_{D B} x\right) I_{1}\left(r_{D w} x\right)\right]},
\end{gathered}
$$


where $q_{h}(r, t)$ is the horizontal specific discharge in the aquifer, and $\Gamma_{h D}\left(r_{D}, t_{D}\right)\left(\equiv \Gamma_{h} / Q\right)$ is the dimensionless total horizontal flux through the aquifer at dimensionless radius $r_{D}$.

Similar to the dimensionless accumulative volume of water, $\overline{V_{v D}}\left(r_{D R}, t_{D}\right)$, leaking through the aquifer-aquitard interface, the dimensionless accumulative volume of water $\overline{V_{h D}}\left(r_{D}, t_{D}\right)$ migrating through the entire aquifer thickness from 0 to time $t$ is obtained as:

$$
\overline{V_{h D}}\left(r_{D R}, t_{D}\right)=\frac{1}{p} \overline{\Gamma_{h D}}\left(r_{D R}, t_{D}\right)
$$

In summary, for a laterally bounded aquifer-aquitard system, Equations (7), (11), (13), (14c), (15c) and (15d) give the analytical solutions to the Laplace transforms of the hydraulic head rise in the aquitard, the hydraulic head rise in the aquifer, the leakage through the aquifer-aquitard interface, the accumulative leakage volume, and the total horizontal flux and the accumulative water volume through the aquifer thickness in their dimensionless form, respectively. Note that using Equations (13) and (15c) we can calculate the dimensionless storage rate of the injected fluid within the aquifer (with a radius of $\left.r_{D}\right): \Gamma_{S D}\left(r_{D}, t_{D}\right)=1-\Gamma_{v D}\left(r_{D}, t_{D}\right)-\Gamma_{h D}\left(r_{D}, t_{D}\right)$.

\subsection{Special Cases of the Bounded-System Solutions}

The "laterally bounded" aquifer-aquitard system with a finite radial extent can be considered as a generalized case of a "laterally infinite" aquifer-aquitard system when the "hypothetical" impervious boundary is located far away from the pressure-perturbation region. Setting $r_{D B} \rightarrow \infty$ in Equations (11), (13), (14c), and (15c) and recalling $K_{1}(\infty)=0$ results in the solutions for an infinite aquifer-aquitard system:

$$
\begin{aligned}
& \overline{h_{D}}\left(r_{D}, p\right)=\frac{2 K_{0}\left(r_{D} x\right)}{r_{D w} p x K_{1}\left(r_{D w} x\right)} . \\
& \overline{\Gamma_{v D}}\left(r_{D R}, p\right)=\frac{\bar{f}}{p x^{2}}\left[1-\frac{r_{D R} K_{1}\left(r_{D R} x\right)}{r_{D w} K_{1}\left(r_{D w} x\right)}\right]
\end{aligned}
$$




$$
\begin{aligned}
& \overline{V_{v D}}\left(r_{D R}, p\right)=\frac{\bar{f}}{p^{2} x^{2}}\left[1-\frac{r_{D R} K_{1}\left(r_{D R} x\right)}{r_{D w} K_{1}\left(r_{D w} x\right)}\right] \\
& \overline{\Gamma_{h D}}\left(r_{D}, p\right)=\frac{r_{D} K_{1}\left(r_{D} x\right)}{r_{D w} p K_{1}\left(r_{D w} x\right)}
\end{aligned}
$$

Equation (16a) for a "laterally infinite" aquifer-aquitard system is identical to the solution given by Moench (1985) in his Equation (25), when the wellbore storage and skin effect are assumed to be negligible. Equations (7) and (16) can be used to calculate the Laplace transforms of hydraulic head rise in the aquifer and the aquitard, the rate of leakage through the aquifer-aquitard interface, the accumulative leakage volume, and the total horizontal flux, respectively, for a "laterally infinite" aquifer-aquitard system.

Now we proceed to compare our solutions with other existing solutions given by Hantush and Jacob (1955) and Hantush (1960) for drawdown analysis, and given by Zhan and Bian (2006) for estimating leakage rate. When the pumping well has an infinitesimal radius (i.e., $r_{w} \rightarrow 0$ ), the drawdown solution from Equation (16a), by recalling $\lim _{y \rightarrow 0} y K_{1}(y)=1$, is as follows:

$$
\overline{h_{D}}\left(r_{D}, p\right)=\frac{2}{p} K_{0}\left(r_{D} x\right)
$$

In the case of negligible aquitard storage, by recalling $\lim _{m \rightarrow 0} m \operatorname{coth}(m)=1$ and $\lim _{m \rightarrow 0} m \tanh (m)=0$, we arrive at

$$
x=\sqrt{p+\bar{f}}=\left\{\begin{array}{l}
{\left[p+\lambda^{2}\right]^{1 / 2}, \text { in Case } 1} \\
p^{1 / 2}, \text { in Case } 2
\end{array}\right.
$$

and in the case of sufficiently large storage in the aquitard, we obtain

$$
x=\sqrt{p+\bar{f}}=\left\{\begin{array}{l}
{\left[p+\lambda^{2} m \operatorname{coth}(m)\right]^{1 / 2}, \text { in Case1 }} \\
{\left[p+\lambda^{2} m \tanh (m)\right]^{1 / 2}, \text { in Case2 }}
\end{array}\right.
$$


Note that for an aquitard with no storage and impervious boundary at the top, the solution in Equation (17a) with Equation (17b) for Case 2 is exactly the same as the Theis solution in the Laplace domain (Theis, 1935). The solution in Equation (17a) with Equation (17b) for Case 1 is identical to the solution given by Hantush and Jacob (1955). The solutions in Equation (17a) with Equation (17c) for both cases are the same as the solutions of Hantush (1960), although Hantush gave approximate analytical solutions for early and late times.

Under the assumptions of (1) an infinitesimal injection-zone radius and (2) no aquitard storage, Equation (16b) becomes:

$$
\overline{\Gamma_{v D}}\left(r_{D R}, p\right)=\frac{\bar{f}}{p x^{2}}\left[1-\left(r_{D R} x\right) K_{1}\left(r_{D R} x\right)\right],
$$

with $\bar{f}=\lambda^{2}$ and $x=\sqrt{p+\lambda^{2}}$. Note that Equation (18) is identical to the leakage solutions given by Zhan and Bian (2006) in their Equation (11).

In summary, the derived analytical solutions in the Laplace domain for a laterally bounded aquifer-aquitard system are generalized solutions to the existing analytical or semi-analytical solutions for a laterally infinite system. When the injection rate is very large and the system's specific storativity (or pore compressibility) is relatively small, the existing solutions for infinite aquifers may not be applicable, because pressure perturbation encounters the aquifer's lateral boundary. The new solutions derived in this paper are applicable to both laterally bounded and infinite systems.

\section{Scale Invariance of Total Leakage Rate and Volume}

\subsection{Scale-Invariant Total Leakage Rate and Volume}

For a laterally bounded aquifer-aquitard system, the total leakage rate $T(t)\left(\equiv \Gamma_{v}\left(r_{B}, t\right)\right)$ is defined as the leakage rate integrated from the edge of the injection zone (or wellbore) (i.e., $r=r_{w}$ and $r_{D}=r_{D w}$ ) to the outer radial boundary (i.e., $r_{R}=r_{B}$ and $r_{D R}=r_{D B}$ ) (Butler and Tsou, 2003; Zhan and Bian, 2006). By definition, the Laplace transform, $\overline{T_{D}}(p)$, of the dimensionless total leakage rate is obtained as: 


$$
\overline{T_{D}}(p)=\overline{\Gamma_{v D}\left(r_{D B}, t\right)}=\overline{\Gamma_{v D}}\left(r_{D B}, p\right)=\frac{1}{2} \int_{r_{D w}}^{r_{D B}} r_{D} \overline{w_{D}^{\prime}} d r_{D} .
$$

Using Equations (13) and (14c) leads to the following dimensionless total leakage rate and volume in the Laplace domain:

$$
\begin{aligned}
& \overline{T_{D}}(p)=\frac{\bar{f}}{p(p+\bar{f})} \\
& \overline{V_{v D}}\left(r_{D B}, p\right)=\frac{\bar{f}}{p^{2}(p+\bar{f})}
\end{aligned}
$$

As indicated in Equation (20), the dimensionless total leakage rate and volume in the Laplace domain, $\overline{T_{D}}(p)$ and $\overline{V_{v D}}\left(r_{D B}, p\right)$, are dependent only on $\bar{f}$ and the $p$ variable (representing time). From the parameter definitions in Equations (4f), (5e), and (6d), we know that the dimensionless total leakage rate and volume depend only on the hydrogeologic properties of the aquifer-aquitard system (i.e., $\lambda$ and $\sigma$ for the contrast of hydraulic conductivity and specific storativity between the aquifer and the aquitard), the thickness of the aquifer and the aquitard, and the time since injection starts. It is apparent that $\overline{T_{D}}(p)$ and $\overline{V_{v D}}\left(r_{D B}, p\right)$ are independent of the radial extent of the bounded aquiferaquitard system and of the radius of the injection zone. This indicates that the total leakage rate and volume in the real time domain is scale invariant.

For an infinite system, setting $r_{D R} \rightarrow \infty$ in Equations (16b) and (16c) and recalling that $\lim _{y \rightarrow \infty} y K_{1}(y)=0$ leads to an expression for the dimensionless total leakage rate and volume in the Laplace domain, which are exactly the same as Equations (20a) and (20b). As a result, a laterally infinite aquifer-aquitard system has the same total leakage rate and volume as a laterally bounded system, provided that the same pumping/injection rate is used. Equation (20) can be used to calculate the Laplace-transformed total leakage rate and volume for the entire aquifer-aquitard interface, for both a "laterally bounded" system and an infinite system. 


\subsection{Asymptotic Approximations}

The early-time and late-time asymptotic approximations for the total leakage rate can be obtained through the analytical inverse Laplace transforms of the approximations to Equation (20). Considering the fact that the hyperbolic tangent and cotangent in Equation (8) approach unity as their argument becomes large $(m>3.0)$ (Moench, 1985, Page 1128), we can obtain the early-time approximation $\left(t_{D}<0.11 \sigma / \lambda^{2}\right)$ :

$$
\overline{T_{D}}(p)=\frac{\lambda \sqrt{\sigma}}{p(\sqrt{p}+\lambda \sqrt{\sigma})}
$$

for Cases 1 and 2.

Considering the fact that the hyperbolic tangent approaches the value of its argument and the hyperbolic cotangent approaches the inverse of its argument as their argument becomes small ( $m<0.316$ ), we can obtain the late-time approximations $\left(t_{D}>10 \sigma / \lambda^{2}\right)$ :

$$
\overline{T_{D}}(p)=\left\{\begin{array}{l}
\frac{\lambda^{2}}{p\left(p+\lambda^{2}\right)}, \text { in Case } 1 \\
\frac{\sigma}{p(1+\sigma)}, \text { in Case } 2
\end{array}\right.
$$

Analytical inversion of the Laplace transforms in Equation (22) results in:

$$
T_{D}\left(t_{D}\right)=\left\{\begin{array}{l}
1-\exp \left(-\lambda^{2} t_{D}\right), \text { in Case } 1 \\
\frac{\sigma}{1+\sigma}, \text { in Case } 2
\end{array}\right.
$$

As shown in Equation (23), when the aquitard top is impervious to flow (i.e., Case 2), the total leakage rate through the aquifer-aquitard is $T_{D}\left(t_{D}\right)=\frac{S_{{ }_{s}} B^{\prime}}{S_{s} B+S_{{ }_{s}} B^{\prime}}$. This indicates that $T_{D}\left(t_{D}\right)$ depends only on the ratio between the injected fluid stored in the aquitard 
$\left(S_{s}^{\prime} B^{\prime}\right)$ and the total injected fluid $\left(S_{s} B+S_{s}^{\prime} B^{\prime}\right)$ stored in the entire aquifer-aquitard system. When the aquitard top is open to an infinite reservoir (i.e., Case 1), eventually the native fluid leaks (at the equivalent volumetric rate of injected fluid) out of the aquiferaquitard system through the aquitard top boundary (as well as through the aquiferaquitard interface), and a steady-state condition is reached for the entire system. The time needed to reach the steady-state condition depends on the hydrogeologic parameters $\sigma$ and $\lambda$, as well as the injection rate.

The scale invariance of the total leakage rate and volume has been mathematically proven in a general, but straightforward, way for a "laterally bounded" radial system. This proof is more general than that given by Butler and Tsou (2003), who used image well theory and numerical modeling to account for the total leakage of a finite-size rectangular aquifer with zero-radius of the injection zone. The scale-invariant phenomenon indicates that the total leakage rate and volume are independent of the radius of the injection zone and the lateral extent of the aquifer. They depend only on the hydrogeologic properties of the aquifer-aquitard system, the thicknesses of the aquifer and the aquitard, and the time since injection starts (i.e., $\lambda, \sigma$, and $t$ ). Considering that the scale-invariant phenomenon has been proved for a "laterally bounded" radial system in this paper and for a rectangular system in Butler and Tsou (2003), it is expected that the scale-invariance is valid for any aquifer-aquitard system with a wide range of more complicated aquifer geometries.

\section{Physical Interpretation of the Solutions}

To physically interpret the analytical solutions given in Equations (11), (13), and (15c) for the hydraulic head rise in the aquifer, the leakage through the aquifer-aquitard interface, and the horizontal flux, we compared the first and the second terms in the denominators of these equations, by evaluating the value of the $E$ ratio:

$$
E\left(r_{D w}, r_{D B}, x\right)=\frac{K_{1}\left(r_{D B} x\right) / I_{1}\left(r_{D B} x\right)}{K_{1}\left(r_{D w} x\right) / I_{1}\left(r_{D w} x\right)} .
$$


Using the approximations: $\quad y^{-1} I_{1}(y)=0.5+O\left(y^{2}\right) \quad$ and $\quad y K_{1}(y)=1+O\left(y^{2}\right)$ (Abramowitz and Stegun, 1972, pp. 378-379), we obtain:

$$
E\left(r_{D w}, r_{D B}, x\right) \leq E\left(r_{D w}, r_{D B}, x \rightarrow 0\right)=\left(\frac{r_{D w}}{r_{D B}}\right)^{2}
$$

When $r_{D B} / r_{D w} \geq 10$, the $E$ ratio can be approximated by zero, with an approximation error less than 1\%. To demonstrate the approximation errors for a variety of $r_{D w}$ and $r_{D B}$, we used four values of the dimensionless injection-zone radius $\left(r_{D w}=0.01,0.1,1.0,10.0\right)$, and two reasonable values of the dimensionless aquifer's radial extent $\left(r_{D B}=100,1000\right)$. Figure 2 shows the dependence of the $E$ ratio on the variables $x$ in the Laplace domain, the dimensionless radius of the injection zone $\left(r_{D w}\right)$, and the dimensionless radial extent of the aquifer $\left(r_{D B}\right)$. The $E$ ratio increases as the variable $x$ decreases and approaches a constant value, transitioning from an initially transient condition (relatively large $x$ ) to a steady-state condition (relatively small $x$ ). In general, the $E$ ratio is smaller than 0.01 as long as the ratio $r_{D B} / r_{D w} \geq 10$ as indicated by Equation (25).

Considering the negligible $E$ ratio when $r_{D B} / r_{D w} \geq 10$, the analytical solutions in Equations (11), (13), (15c) can be rewritten in their approximate form:

$$
\begin{aligned}
& \overline{h_{D}}\left(r_{D}, p\right)=\frac{2 K_{0}\left(r_{D} x\right)}{r_{D w} p x K_{1}\left(r_{D w} x\right)}+\frac{2 K_{1}\left(r_{D B} x\right) I_{0}\left(r_{D} x\right)}{r_{D w} p x K_{1}\left(r_{D w} x\right) I_{1}\left(r_{D B} x\right)} \\
& \overline{\Gamma_{v D}}\left(r_{D R}, p\right)=\frac{\bar{f}}{p x^{2}}\left[1-\frac{r_{D R} K_{1}\left(r_{D R} x\right)}{r_{D w} K_{1}\left(r_{D w} x\right)}\right]+\frac{\bar{f}}{p x^{2}} \frac{r_{D R}\left[K_{1}\left(r_{D B} x\right) I_{1}\left(r_{D R} x\right)\right]}{r_{D w}\left[I_{1}\left(r_{D B} x\right) K_{1}\left(r_{D w} x\right)\right]} \\
& \overline{\Gamma_{h D}}\left(r_{D}, p\right)=\frac{r_{D} K_{1}\left(r_{D} x\right)}{r_{D w} p K_{1}\left(r_{D w} x\right)}-\frac{r_{D}}{r_{D w} p} \frac{K_{1}\left(r_{D B} x\right) I_{1}\left(r_{D} x\right)}{K_{1}\left(r_{D w} x\right) I_{1}\left(r_{D B} x\right)} .
\end{aligned}
$$

We compared Equation (26), the approximate solutions for a laterally bounded system, to Equation (16), the solutions for a laterally infinite system, for the hydraulic head rise, the leakage rate, or the horizontal flux. The approximate analytical solution for a bounded 
aquifer consists of the solution for an infinite system and a term reflecting the effect of the impervious lateral boundary. This boundary-effect term depends on the dimensionless radial extent $r_{D B}$, because of the presence of $K_{1}\left(r_{D B} x\right)$ and $I_{1}\left(r_{D B} x\right)$ in Equation (26).

As implied by Equation (26a), the hydraulic head rise at a given $r_{D}$ in a bounded aquifer is higher than that in an infinite system of the same $\lambda$ and $\sigma$ values. The extra head rise, represented by the boundary-effect term, results in a higher rate of flow through the aquifer-aquitard interface. The enhanced flow rate occurs over the entire bounded system and leads to a higher leakage rate $\overline{\Gamma_{v D}}\left(r_{D R}, p\right)$, as shown by the second term in Equation (26b). It is this self-adjusting nature of the bounded aquifer-aquitard system that results in the scale invariance of the total leakage rate. Furthermore, as shown in Equations (13) and (20a), the leakage rate $\overline{\Gamma_{v D}}\left(r_{D R}, p\right)$ in the Laplace domain changes from 0 at the edge of the wellbore or injection zone $\left(r_{D}=r_{D w}\right)$ to $\overline{T_{D}}(p)(\equiv \bar{f} / p(p+\bar{f}))$ at the impervious radial boundary $\left(r_{D}=r_{D B}\right)$. However, between these two end values, $\overline{\Gamma_{v D}}\left(r_{D R}, p\right)$ depends on $r_{D R}$ in a complicated form (to be shown in Section 5.2).

Note that in the above physical interpretation of the derived analytical solutions in the Laplace domain (as well as in the mathematical formulations), it is assumed that no changes in the $\lambda$ and $\sigma$ parameter are caused by pressure increase from the initial hydrostatic pressure. This implies that geomechanical damage caused by overpressure needs be avoided (USEPA, 1994; Zhou et al., 2008). The sustainable injection rate (or the injection time for a given injection rate) can be easily calculated using Equation (11), when the maximum sustainable pressure is known.

\section{Solution Evaluation}

The analytical solutions presented in Sections 2 and 3 are applied in this section. We used numerical inversion of the Laplace transforms in these analytical solutions to obtain the pressure perturbation (or hydraulic head drawdown/rise), leakage rate, and total leakage rate in the real time domain. An example of a large-scale injection in a deep sedimentary 
sandstone aquifer was used to evaluate the solutions for a laterally bounded aquiferaquitard system.

\subsection{Numerical Inversion}

In general, no analytical inverse Laplace transforms of the solutions presented in Sections 2 and 3 exist, and numerical inversion is needed. A number of numerical methods for Laplace transform inversion are available (Cohen, 2007). Among them, the methods of Stehfest (1970) and de Hoog et al. (1982) have been extensively employed with semianalytical solutions developed for field pumping and tracer tests (e.g., Moench, 1985; Moridis, 1999; Zhan and Bian, 2006; Zhou et al., 2007). In this research, the de Hoog et al. (1982) method was employed for numerical inversion of our analytical solutions. The code was verified by comparing our solutions with the solutions presented in Figure 2b of Moench (1985) for the Theis model and the Moench model with no skin effect and wellbore storage. The hydrogeologic parameters used are $\lambda=0.004$ and $\sigma=100$, with the dimensionless radius of the observations at $r_{D}=10$. We applied the models to both Cases 1 and 2 for comparison, and added the underlying aquitard of the same properties as the overlying aquitard. An excellent agreement for both the Theis and Moench models between our solution and Moench's solution was achieved (not shown), indicating that the numerical inversion of the Laplace transforms of analytical solutions works well. The FORTRAN code used in this paper can be obtained from the corresponding author upon request.

\subsection{Behavior of Hydraulic Head Rise and Leakage in a Bounded System}

A typical example for large-scale deep injection was used to demonstrate the behavior of hydraulic head rise and leakage in a laterally bounded brine aquifer. In the example, it was assumed that an equivalent volume of native brine is injected into the brine aquifer at a constant volumetric injection rate. (This example was extracted from a typical problem for industrial-scale injection of $\mathrm{CO}_{2}$ into a deep sedimentary sandstone-brine aquifer (Birkholzer et al., 2008; Zhou et al., 2008) by neglecting the two-phase $\mathrm{CO}_{2}$-brine flow regime, which cannot be represented by the developed analytical solutions.) The following properties were used: aquifer permeability of $k=10^{-13} \mathrm{~m}^{2}$, aquifer pore 
compressibility of $\beta_{p}=4.5 \times 10^{-10} \mathrm{~Pa}^{-1}$, aquifer thickness of $60 \mathrm{~m}$, aquitard permeability of $k^{\prime}=10^{-18} \mathrm{~m}^{2}$, aquitard pore compressibility of $\beta_{p}^{\prime}=9.0 \times 10^{-10} \mathrm{~Pa}^{-1}$, aquitard thickness of $100 \mathrm{~m}$, and water compressibility of $\beta_{w}=3.5 \times 10^{-10} \mathrm{~Pa}^{-1}$. Accordingly, the hydraulic conductivities of the aquifer and the aquitards are $K=0.20 \mathrm{~m} / \mathrm{day}$ and $K^{\prime}=0.20 \times 10^{-5} \mathrm{~m} /$ day, respectively, assuming brine density of $\rho=1200 \mathrm{~kg} / \mathrm{m}^{3}$, gravity acceleration of $g=9.8 \mathrm{~m} / \mathrm{s}^{2}$, and water viscosity of $\mu=0.5 \times 10^{-3}$ Pa s. The specific storativity of the aquifer is calculated using $S_{s}=\phi \rho g\left(\beta_{w}+\beta_{p}\right)=1.88 \times 10^{-6} \mathrm{~m}^{-1}$, where the aquifers' porosity is $\phi=0.2$. The specific storativity of the aquitards is calculated using $S^{\prime}{ }_{s}=\phi^{\prime} \rho g\left(\beta_{w}+\beta^{\prime}{ }_{p}\right)=1.47 \times 10^{-6} \mathrm{~m}^{-1}$, where the aquitard's porosity is $\phi^{\prime}=0.10$. Based on the above hydrogeologic and geometric properties, we calculated the two model parameters: $\lambda=2.45 \times 10^{-3}$ and $\sigma=1.30$. The additional parameters are: $r_{w}=6.0 \mathrm{~m}, r_{B}=20,000 \mathrm{~m}$ for the bounded system, and the injection rate is $Q=5,700$ $\mathrm{m}^{3} /$ day. An overlying aquitard and an underlying aquitard of the same properties were considered, assuming the conditions of zero hydraulic head rise at the top of the overlying aquitard and the bottom of the underlying aquitard. Because an underlying aquitard is considered, the leakage term $\bar{f}$ in Equation (8) is doubled, and all other solutions remain unchanged. For comparison, an infinite system of the same properties as the bounded system was also considered.

Figure 3 shows the profiles of the dimensionless hydraulic head rise along the radial direction, $h_{D}\left(r_{D}, t_{D}\right)$, as a function of dimensionless time $\left(t_{D}\right)$, for the bounded aquiferaquitard system calculated using Equation (11) and its comparison with those for the infinite system calculated using Equation (16a). At $t_{D}=1.08 \times 10^{3}$ (0.1 year of injection), the injection-induced hydraulic head rise has not reached the outer radial boundary of the bounded system, so that identical profiles are obtained for both the bounded and infinite aquifers. At $t_{D}=1.08 \times 10^{4}$, the hydraulic head rise has just reached the outer radial boundary, but no significant difference in the profiles occurs between the bounded and the infinite systems. Starting with $t_{D}=1.08 \times 10^{4}$, the profile for the bounded aquifer 
deviates from that of the infinite aquifer. At $t_{D}=5.40 \times 10^{4}$, the deviation mainly occurs in the region close to the outer radial boundary. After $t_{D}=1.08 \times 10^{5}$, the profile of the bounded aquifer is significantly different from that of the infinite aquifer over the entire region of $r_{D} \leq 333.3$. The hydraulic head rise in the storage formation gradually increases; a steady-state condition is observed at $t_{D}=1.08 \times 10^{6}$ (100 years of injection) for the bounded system, as no changes are obtained for longer injection time. For the infinite aquifer, however, the condition appears to be at a quasi-steady state after $t_{D}=3.24 \times 10^{5}$ for the inner region $\left(r_{D} \leq 333.3\right)$, while the front of the pressure wave continues to propagate away.

Figure 4 shows the incremental dimensionless hydraulic head rise, $h_{D}\left(r_{D}, t_{D 2}\right)-h_{D}\left(r_{D}, t_{D 1}\right)$, over five intervals of the dimensionless time from 0 to $t_{D}=1.08 \times 10^{6}$. At early time, the incremental head change decreases from the injection zone to the outer radial boundary, as shown for the time intervals from $1.08 \times 10^{3}$ to $1.08 \times 10^{4}$ and from $1.08 \times 10^{4}$ to $5.40 \times 10^{4}$. The shape of the profile of incremental head rise indicates the injection-driven pressure change. After that, the incremental head rise with injection time becomes relatively uniform over the entire bounded aquifer, driven by the needs to store additional injected fluid in the entire aquifer-aquitard system. This pressure change is referred to as storage-driven pressure changes (Zhou et al., 2008).

The profiles of the hydraulic head change along the radial direction determine the shape of the radial profiles of the leakage rate, $\Gamma_{v D}\left(r_{D R}, t_{D}\right)$, as shown in Figure 5 . For the bounded system, the leakage is attributed mainly to the hydraulic head rise in the pressure-perturbation region of $r_{D} \leq 70$ and $r_{D} \leq 300$ at $t_{D}=1.08 \times 10^{3}$ and $1.08 \times 10^{4}$, respectively. Once the pressure wave reaches the outer boundary at approximately $t_{D}=1.08 \times 10^{4}$, the increase in the leakage rate with injection time is attributed to the incremental hydraulic head rise over the entire domain (see Figure 4). The other factor affecting the shape of the leakage-rate profiles is that the aquifer- 
aquitard interface area (i.e., $2 \pi r_{D} \Delta r_{D}$ ) available for leakage per unit $\Delta r_{D}$ increases with $r_{D}$. Because of the radial feature of the bounded system and the relatively uniform incremental hydraulic head rise, the radial profile of the leakage rate changes its shape: when $t_{D}<1.08 \times 10^{4}$, the leakage occurs mainly within the pressure-perturbation region, with a flat line outside of this region; when $t_{D}>1.08 \times 10^{4}$, the slope of the radial profile becomes steeper with $r_{D R}$ (see Figure $5 \mathrm{a}$ ). At $t_{D}=1.08 \times 10^{6}$, the dimensionless total rate of leakage through the entire aquifer-aquitard interface is unity, reaching a steadystate condition for the entire aquifer-aquitard system.

Figure $5 \mathrm{~b}$ shows the radial profile of the leakage rate, $\Gamma_{v D}\left(r_{D R}, t_{D}\right)$, as a function of dimensionless injection time, for a radial distance $r_{D R}<333.3(20 \mathrm{~km})$ for the infinite system. A steady-state leakage rate is obtained for the region $r_{D R}<333.3$ at approximately $t_{D}=1.08 \times 10^{5}$, with the leakage rate of 0.46 at $r_{D R}=333.3$. In other word, $46 \%$ of the injected fluid rate leaks out of the $20 \mathrm{~km}$ domain. Note that the radial profiles of leakage rate at $t_{D}=1.08 \times 10^{5}, 3.24 \times 10^{5}, 1.08 \times 10^{6}$ are essentially the same. The leakage rate at $t_{D}=1.08 \times 10^{3}$, for example, is higher than the steady-state leakage rate for the region $r_{D R} \leq 100$, even though the injection-induced hydraulic head is lower. This anomaly in the leakage rate is attributed to the hydraulic gradient at the aquifer-aquitard interface, which depends on the pressure increase in both the aquifer and the aquitards (see Equation (8) for $\bar{f}$ ). For example, for a given hydraulic head rise in the aquifer at a given $r_{D}$, the diffusive penetration into the aquitards leads to a decrease with time in hydraulic gradient at the aquifer-aquitard interface. On the basis of the proven scale-invariant phenomenon of the total leakage rate, we consider that, for a given time, the difference between the total leakage rate for the bounded aquifer and the leakage rate for $r_{D R}=333.3$ (i.e., $r_{R}=20,000 \mathrm{~m}$ ) of the infinite system can be attributed to the leakage rate for the region $333.3 \leq r_{D R} \leq \infty$ of the infinite system.

Figure 6a shows the evolution of the dimensionless leakage rate, $\Gamma_{v D}\left(r_{D R}, t_{D}\right)$ for the bounded system, as a function of $r_{D R}\left(=0.25,0.50,0.75,0.90,1.00 r_{D B}\right)$. The leakage 
rate monotonically increases with $r_{D R}$ up to the total leakage rate at $r_{D R}=r_{D B}$. The contribution to the total leakage rate from each of the regions (e.g., $0.25 r_{D B} \leq r_{D R} \leq 0.50 r_{D B}$ ) varies with injection time. For example, the contribution from the region $r_{D R} \leq 0.25 r_{D B}$ is dominant at $t_{D}=1.08 \times 10^{3}$, while the contribution from the $0.5 r_{D B} \leq r_{D R} \leq r_{D B}$ region is dominant at later time (e.g., $t_{D}=1.08 \times 10^{6}$ ). For a given $r_{D R}$ value, the leakage rate does not always monotonically change with injection time, depending on the transient hydraulic gradient at the aquifer-aquitard interface as discussed above. The total leakage rate for the entire bounded system, however, increases with time until the system reaches a steady-state condition at $t_{D}=1.08 \times 10^{6}$ with $T_{D}=1.0$. In the steady-state condition, native brine is displaced, at a discharge rate equivalent to the injection rate, into the overlying/underlying formations through the aquitards.

As shown in Figure $6 \mathrm{~b}$, the total horizontal flux, $\Gamma_{h D}\left(r_{D R}, t_{D}\right)$, through the aquifer thickness at a given dimensionless radius, $r_{D R}$, increases with injection time until it becomes constant at approximately $t_{D}=1.08 \times 10^{5}$. This flux provides the fluid mass (1) stored within the subdomain $r_{D R} \leq r_{D} \leq r_{D B}$ in response to continuous pressure increase and (2) leaking through the aquifer-aquitard interface for $r_{D R} \leq r_{D} \leq r_{D B}$. As a result, the total horizontal flux decreases with $r_{D R}$ until it becomes zero at the outer radial impervious boundary. Figure 6c shows the evolution of the dimensionless storage rate, $\Gamma_{S D}\left(r_{D R}, t_{D}\right)$, within the aquifer, as a function of $r_{D R}$. Together, Figure 6 shows the mass balance between the dimensionless injection rate (i.e., unity) and combination of (1) dimensionless storage rate within $r_{D} \leq r_{D R}$, (2) dimensionless total horizontal flux through $r_{D}=r_{D R}$ and (3) dimensionless leakage rate for $r_{D} \leq r_{D R}$, i.e., $\Gamma_{v D}\left(r_{D R}, t_{D}\right)+\Gamma_{h D}\left(r_{D R}, t_{D}\right)+\Gamma_{s D}\left(r_{D R}, t_{D}\right)=1$. Similarly, the accumulative volume of water stored within the aquifer and that leaking through the aquifer-aquitard interface can be calculated using Equations (14c) and (15d). 


\section{Conclusions}

Existing (semi-)analytical solutions developed for analyzing pumping-induced drawdown and leakage in an aquifer-aquitard system assume that the aquifer has an infinite radial extent. Such solutions may not be applicable to a laterally bounded, deep sedimentary aquifer when large-scale injection of fluids is considered. In this case, injection-induced pressure perturbation may reach the natural boundary of the aquifer, increasing pressure over the entire lateral extent of the aquifer, in part because of the relatively low specific storativity or pore compressibility.

We developed new semi-analytical solutions for the injection- (or pumping-) induced pressure perturbation in both the aquifer and the aquitard, and the rate and volume of leakage through the aquifer-aquitard interface. These solutions were developed by coupling the one-dimensional radial flow equation for the aquifer and the onedimensional vertical flow equation for the aquitard. Continuity in pressure and mass flux at the aquifer-aquitard interface was imposed, and the no-flow condition was used at the outer radial boundary. The analytical solutions for the Laplace-transform pressure change, leakage rate, and leakage volume were proved to be the generalized forms of their corresponding solutions for a laterally infinite system. Numerical inversion of these solutions was conducted to analyze the pressure change and leakage in the real time domain.

Our solutions provide a general proof of the scale-invariant phenomenon of the total leakage rate and volume integrated over the entire aquifer-aquitard interface. This phenomenon was found by Butler and Tsou (2003), using image well theory and an existing semi-analytical solution of infinite aquifers, with the aid of an infinite number of image wells. Laplace transforms of total leakage rate and volume were demonstrated to be independent of the radial extent of the aquifer, regardless of a bounded or an infinite aquifer. The total leakage rate and volume depend only on the hydraulic conductivity and specific storativity of the aquifer and the aquitard, as well as on the duration for injection or injection time. The scale-invariant phenomenon reflects the self-adjusting nature of an aquifer-aquitard system (whether it is bounded or infinite): a higher pressure increase 
within a smaller bounded system results in a higher leakage flux through per unit area of the aquifer-aquitard interface.

\section{Acknowledgements}

The authors wish to thank George Moridis at Lawrence Berkeley National Laboratory (LBNL) for his careful internal review of the manuscript. Thanks are also due to two anonymous reviewers for their constructive suggestions for improving the quality of the manuscript. This work was funded by the Assistant Secretary for Fossil Energy, Office of Sequestration, Hydrogen, and Clean Coal Fuels, National Energy Technology Laboratory, of the U.S. Dept. of Energy, and by Lawrence Berkeley National Laboratory under Contract No. DE-AC02-05CH11231.

\section{References}

Abramowitz, M., Stegun, I.A.: Handbook of Mathematical Functions with Formulas, Graphs, and Mathematical Tables. Dover Publications, Inc., New York (1972)

Batu, V.: Aquifer Hydraulics: A Comprehensive Guide to Hydrogeologic Data Analysis. John Wiley, New York (1998)

Bear, J.: Dynamics of Fluids in Porous Media. Dover Publications, New York (1972)

Birkholzer, J.T., Zhou, Q., Tsang, C.-F.: Large-scale impact of $\mathrm{CO}_{2}$ storage in deep saline aquifers: A sensitivity study on pressure response in stratified systems. Int. J. Greenhouse Gas Control (in press)

Butler, J.J., Tsou, M.: Pumping-induced leakage in a bounded aquifer: An example of a scale-invariant phenomenon. Water Resour. Res. 39(12), 1344, doi:10.1029/2002WR001484 (2003)

Cheng, A.H.D., Morohunfola, O.K.: Multilayered leaky aquifer systems: Pumping well solutions. Water Resour. Res. 29(8), 2787-2800 (1993)

Cheng, A.H.D.:, Multilayered Aquifer Systems- Fundamentals and Applications. Marcel Dekker, New York (2000)

Cohen, A.M.: Numerical Methods for Laplace Transform Inversion. Springer, New York (2007)

de Hoog, F.R., Knight, J.H., Stokes, A.N.: An improved method for numerical inversion of Laplace transforms. SIAM J. Sci. Stat. Comput. 3, 357-366 (1982)

Earlougher, R.C: Advances in Well Test Analysis. Henry L. Doherty Memorial Fund of AIME, New York (1977)

Hantush, M.S.: Modification of the theory of leaky aquifers. J. Geophys. Res. 65(11), 3713-3725 (1960) 
Hantush, M.S.: Hydraulics of wells, in Advances in Hydroscience, Chow, V. T. (ed.). Academic Press, New York (1964)

Hantush, M.S., Jacob, C.E.: Nonsteady radial flow in an infinite leaky aquifer. Eos Trans. AGU, 36(1), 95-100 (1955)

Konikow, L.F., Neuzil, C.E.: A method to estimate groundwater depletion from confining layers. Water Resour. Res. 43, W07417, doi:10.1029/2006WR005597 (2007)

Moench, A.F.: Transient flow to a large-diameter well in an aquifer with storative semicofining layers. Water Resour. Res. 21(8), 1121-1131 (1985)

Moridis, G.: Semianalytical solutions for parameter estimation in diffusion cell experiments. Water Resour. Res. 35, 1729-1740 (1999)

Neuman, S.P., Witherspoon, P.A.: Theory of flow in a two-aquifer system. Water Resour. Res. 5(4), 803-816 (1969)

Ramakrishnan, T.S., Kuchuk, F.J.: Pressure transients during injection: Constant rate and convolution solutions. Transport Porous Media 10, 103-136 (1993)

Stehfest, H.: Numerical inversion of Laplace transforms. Commun. ACM 13(1), 47-49 (1970)

Streltsova, T.D.: Well Testing in Heterogeneous Formations. Wiley, New York (1988)

Theis, C.V.: The relation between the lowering of the piezometric surface head and the rate and duration of discharge of a well using ground-water storage. Eos Trans. AGU 16, 519-524 (1935)

USEPA (U.S. Environmental Protection Agency): Determination of maximum injection pressure for Class I wells, United States Environmental Protection Agency Region 5underground injection control section regional guidance \#7. EPA, Washington DC (1994) (URL: http://www.epa.gov/R5water/uic/r5guid/r5_07.htm)

Vukovic, M., Soro, A.: Hydraulics of Water Wells: Theory and Application. Water Resources Publications, Littleton, CO (1992)

Zhan, H., Bian, A.: A method of calculating pumping-induced leakage. J. Hydrol., 328, 657-667 (2006)

Zhou, Q., Bensabat, J., Bear, J.: Accurate calculation of specific discharge in heterogeneous porous media. Water Resour. Res. 37(12), 3057-3070 (2001)

Zhou, Q., Liu, H.-H., Molz, F.J., Zhang, Y., Bodvarsson, G.S.: Field-scale effective matrix diffusion coefficient for fractured rock: Results from literature survey. J. Contam. Hydrol. 93, 161-187 (2007)

Zhou, Q., Birkholzer, J.T., Tsang, C.-F., Rutqvist, J.: A method for quick assessment of $\mathrm{CO}_{2}$ storage capacity in closed and semi-closed saline formations. Int. J. Greenhouse Gas Control, doi:10.1016/j.ijggc.2008.02.004 (2008) 
Figure 1. Schematic showing a laterally bounded aquifer, with an overlying aquitard and an underlying impervious layer

Figure 2. Dependence of the $E$ ratio on the variable $x=\sqrt{p+\bar{f}}$, the dimensionless radius of the injection zone $r_{D w}$, and the dimensionless radial extent of the aquifer $r_{D B}$

Figure 3. Radial profiles of the dimensionless hydraulic head rise, as a function of dimensionless injection time, at (a) early time and (b) later time

Figure 4. Radial profiles of the incremental dimensionless hydraulic head rise in the bounded aquifer for five intervals of dimensionless time

Figure 5. Radial profiles of the dimensionless leakage rate, $\Gamma_{v D}\left(r_{D R}, t_{D}\right)$, through the aquifer-aquitard interface, as a function of dimensionless injection time, for (a) the laterally bounded aquifer and (b) the infinite system. Note that (b) shows only a portion (close to the injection zone) of the infinite system

Figure 6. Evolution of (a) the dimensionless leakage rate, $\Gamma_{v D}\left(r_{D R}, t_{D}\right)$, through the aquifer-aquitard interface, (b) the dimensionless horizontal flux, $\Gamma_{h D}\left(r_{D R}, t_{D}\right)$, through the aquifer thickness, and (c) the dimensionless storage rate, $\Gamma_{s D}\left(r_{D R}, t_{D}\right)$, of the injected fluid in the aquifer for the bounded aquifer-aquitard system, as a function of the dimensionless integrated radius $r_{D R}$. Note that the leakage rate approaches the total leakage rate as the integrated $\quad r_{D R} \rightarrow r_{D B}$ and $\Gamma_{v D}\left(r_{D R}, t_{D}\right)+\Gamma_{h D}\left(r_{D R}, t_{D}\right)+\Gamma_{s D}\left(r_{D R}, t_{D}\right)=1$ 


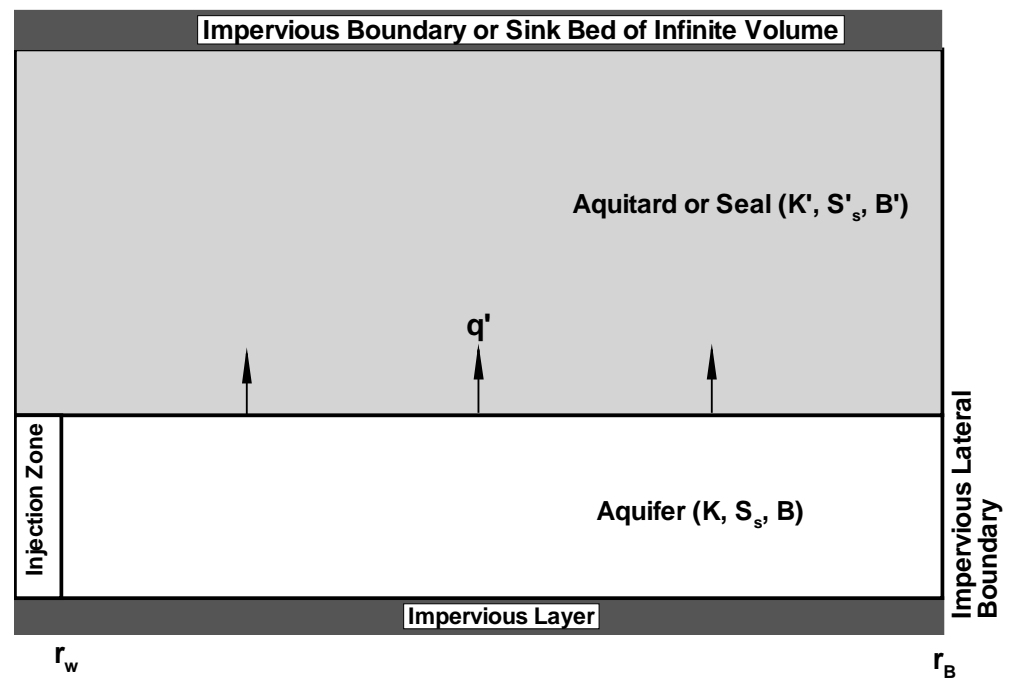

Figure 1.
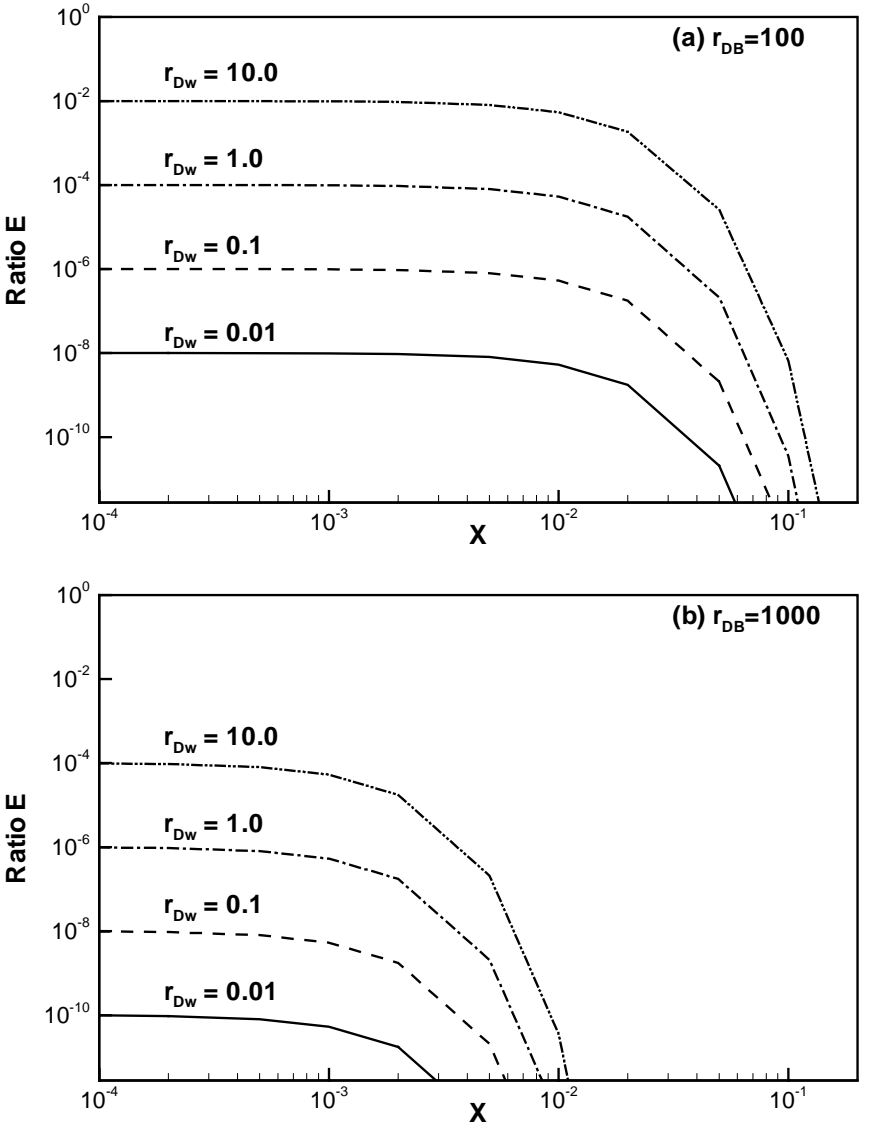

Figure 2. 

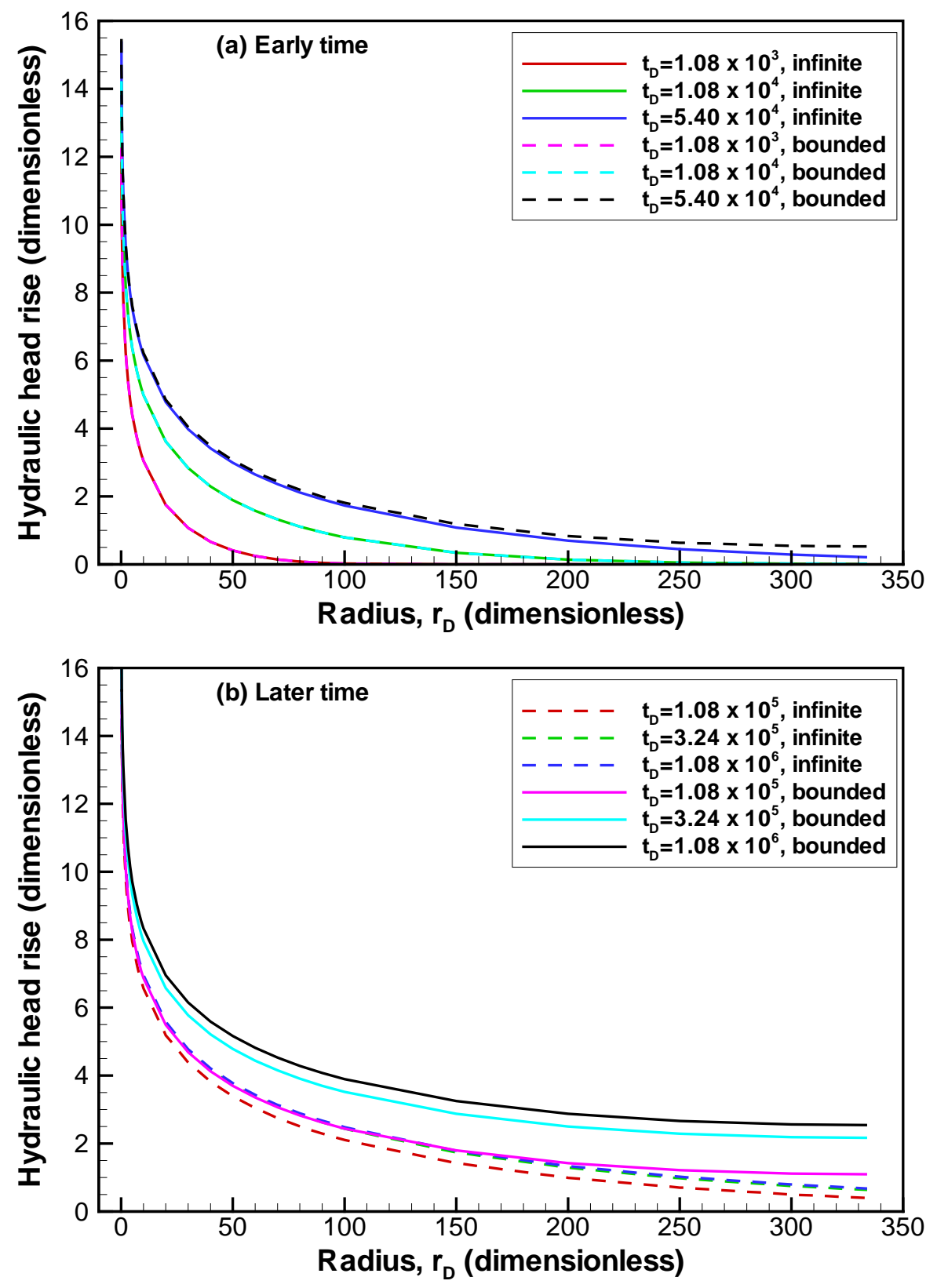

Figure 3. 


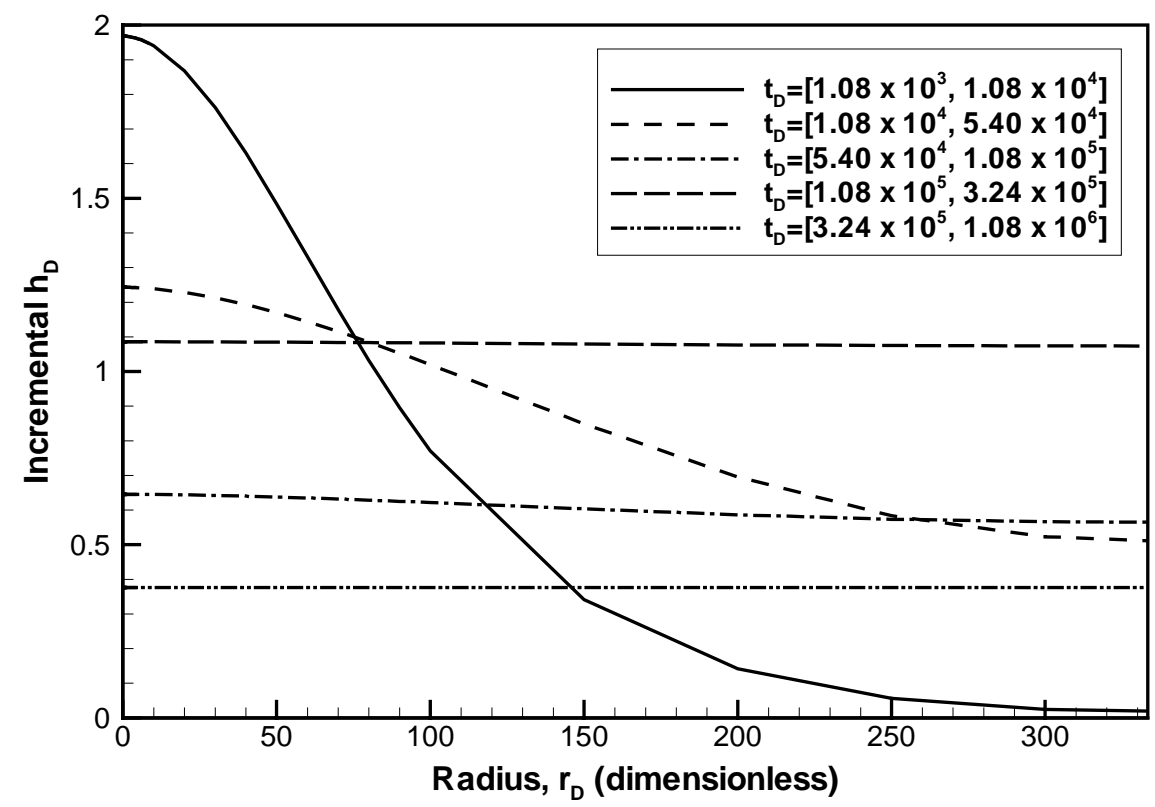

Figure 4 

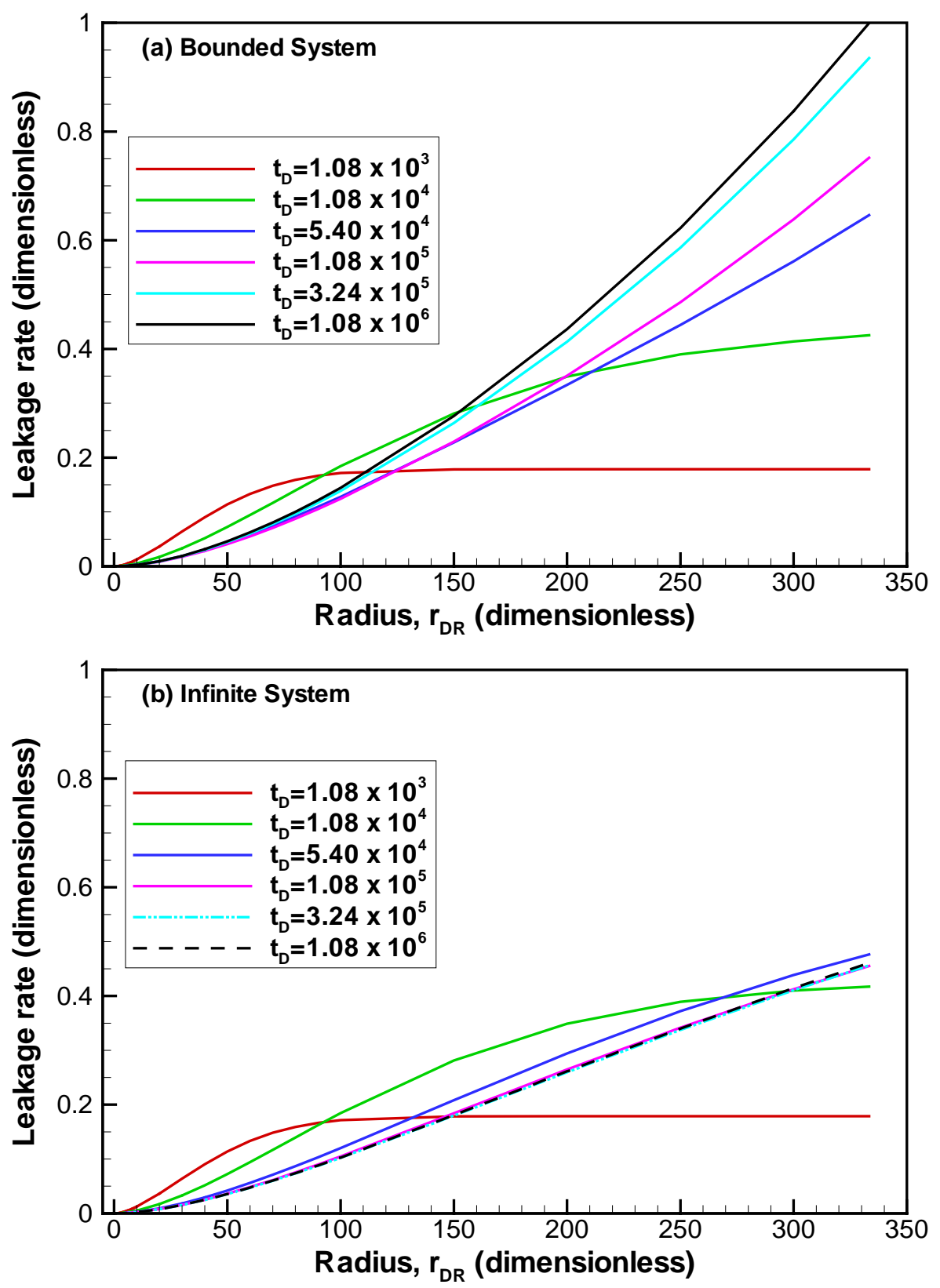

Figure 5. 

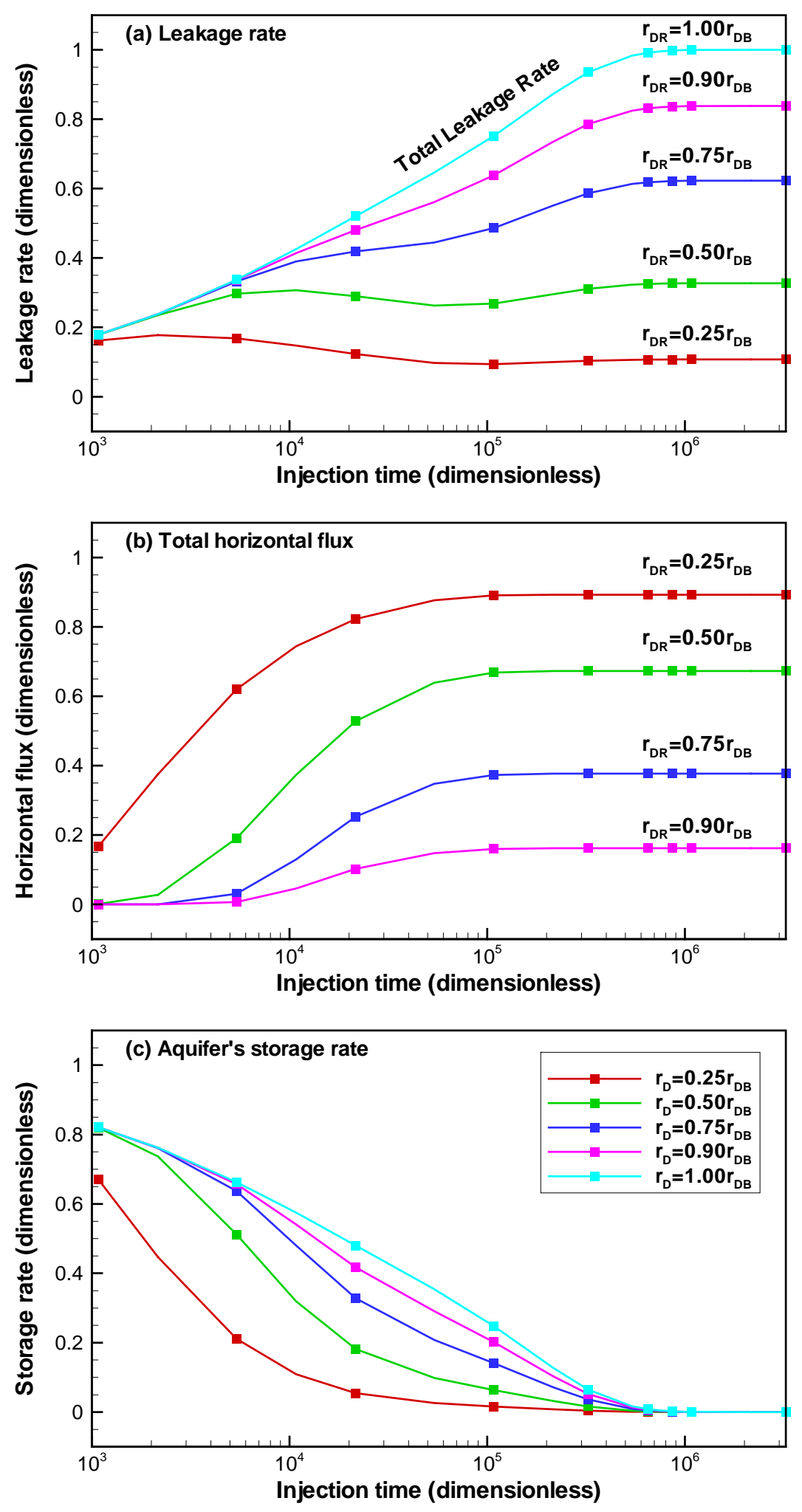

Figure 6. 